UCRL-JC-127771

PREPRINT

\title{
Electrostatic Comb Drive for Vertical Actuation
}

A. P. Lee

C. F. McConaghy

P. A. Krulevitch

E. W. Campbell

G. E. Sommagren

J. C. Trevino

This paper was prepared for submittal to the The International Society for Optical Engineers Micromachining and Microfabrication Conference

Austin, Texas

September 29-30, 1997

July 10, 1997

This is a preprint of a paper intended for publication in a journal or proceedinga. Since changes may be made before publication, this preprint is made available with the underotanding that it will not be cited or reproduced without the permiecion of the author. 


\section{DISCLAIMER}

This document was prepared as an account of work sponsored by an agency of the United States Government. Neither the United States Government nor the University of California nor any of their employees, makes any warranty, express or implied, or assumes any legal liability or responsibility for the accuracy, completeness, or usefulness of any information, apparatus, product, or process

disclosed, or represents that its use would not infringe privately owned rights. Reference herein to any specific commercial product, process, or service by trade name, trademark, manufacturer, or otherwise, does not necessarily constitute or imply its endorsement, recommendation, or favoring by the United States Government or the University of California. The views and opinions of authors expressed herein do not necessarily state or reflect those of the United States Government or the University of California, and shall not be used for advertising or product endorsement purposes. 


\title{
Electrostatic comb drive for vertical actuation
}

\author{
Abraham P. Lee, Chuck F. McConaghy, Peter A. Krulevitch, Eugene W. Campbell, Gary E. Sommargren, \\ Jimmy C. Trevino*
}

Lawrence Livermore National Laboratory, MS L-222, Livermore, CA 94550

Microtechnology Center, Electronics Engineering Technologies Division

Keywords: electrostatic comb drive, vertical actuation, vertical position control, interferometry

\begin{abstract}
The electrostatic comb finger drive has become an integral design for microsensor and microactuator applications. This paper reports on utilizing the levitation effect of comb fingers to design vertical-to-the-substrate actuation for interferometric applications. For typical polysilicon comb drives with $2 \mu \mathrm{m}$ gaps between the stationary and moving fingers, as well as between the microstructures and the substrate, the equilibrium position is nominally $1-2 \mu \mathrm{m}$ above the stationary comb fingers. This distance is ideal for many phase shifting interferometric applications. Theoretical calculations of the vertical actuation characteristics are compared with the experimental results, and a general design guideline is derived from these results. The suspension flexure stiffnesses, gravity forces, squeeze film damping, and comb finger thicknesses are parameters investigated which affect the displacement curve of the vertical microactuator. By designing a parallel plate capacitor between the suspended mass and the substrate, in situ position sensing can be used to control the vertical movement, providing a total feedback-controlled system. Fundamentals of various capacitive position sensing techniques are discussed. Experimental verification is carried out by a Zygo distance measurement interferometer.
\end{abstract}

\section{INTRODUCTION}

The laterally driven electrostatic comb drive resonant structure has become an integral component in numerous MEMS devices over the last 8 years ${ }^{1}$. Applications are very broad and include accelerometers ${ }^{3-6}$, gyroscopes ${ }^{7}$, impact actuators ${ }^{8}$, micromechanical filters ${ }^{9}$, and micromechanical voltmeters ${ }^{10}$. Most of these devices utilize the lateral motion of engaging and disengaging the interdigitated comb fingers. Constant electrostatic force is generated with an applied DC bias voltage ${ }^{1}$, independent of the position of the suspended mass. This same device generates a levitation force on the suspended structure as a bias voltage is applied, due to the asymmetric distribution of the electrical fields ${ }^{11}$. However, this levitation force is often the source of unwanted out-of-plane motion causing tilting to many laterally-driven sensors and actuators ${ }^{11}$. One exception is in the accelerometer designed and fabricated by Yun and $\mathrm{Howe}^{3}$, where the levitation force was designed to provide the feedback force for a $\Sigma-\Delta$ sensing loop. Comb finger drives have also been applied towards integrated micro optical systems ${ }^{12}$. By combining comb fingers with microfabricated hinges ${ }^{13}$, many devices including laser-fiber packaging modules ${ }^{14}$, micro optical scanners ${ }^{15}$, and even raster-scanning displays have been demonstrated ${ }^{16}$.

Parallel motion of micromirrors can be used for interferometry in phase shifting, modulating Fabry-Perot cavities, or the construction of external-cavity semiconductor-laser modules. For vertical out-of-the-plane actuation in optical applications, most existing devices are used as tilting mirrors for imaging, displays ${ }^{17}$, or scanning. Parallel motion micromirrors by Comtois et al. ${ }^{18}$ utilize parallel plate capacitive configurations where a suspended micromirror is attracted to a bottom plate via an electrostatic force. The parallel plate configuration has an unstable region where the mirror will collapse against the bottom plate with infinitesimal amount of electrostatic force, and stand-offs must be designed to avoid shorting out the biased electrodes.

Interferometry is an ideal application for electrostatically-driven microactuators because the required actuation force is low

*. Further author information -

A.P.L. (correspondence): Email: lee60@llnl.gov; Telephone: 510-423-4524; Fax: 510-422-2783

C.F.M.: Email: mcconaghy1@llnl.gov; P.A.K.: krul@1lnl.gov; G.E.S.: sommargren1 @llnl.gov; E.W.C.: campbell33@llnl.gov; J.C.T.: trevino1@llnl.gov 
and controlled displacements in the nanometer range are possible. Phase shifting interferometry involves the combination of a test wavefront generated by an unknown optical component, such as a lens or mirror, with a known reference wavefront, allowing for precise measurement of the unknown component's optical properties ${ }^{25}$. The interference pattern generated by the test and reference waves is recorded a number of times while the phase of the reference wavefront is shifted by a known amount between measurements. By using a detector array, such as a CCD camera, and a computer, measurements can be made simultaneously at a large number of points covering the interference pattern. Given the properties of the reference wave, these time sequenced measurements can be used to calculate the properties of the test wave ${ }^{26}$. However, to obtain accurate results, it is necessary that the phase shift be accurately known. For this reason, the phase shifting component must yield an accurate and repeatable phase shift over the entire range of phases.

Applications of electrostatic vertical microactuators with displacements less than $2 \mu \mathrm{m}$ are mostly optical. Phase shifting interferometry is one significant application, and a variety of phase shifting methods exist ${ }^{26}$. The most common technique is the use of a piezoelectric transducer (PZT) to move a reference surface ${ }^{27}$. For example, it is by this method that commercial interferometer manufacturers Wyko and Zygo provide phase shifting for their Fizeau interferometers and interference microscopes. Other methods that produce a change of phase at fixed optical frequency include tilting a glass plate ${ }^{28}$, translating a diffraction grating ${ }^{29}$, using PZT to strain an optical fiber ${ }^{30}$, and using an electro-optic modulator ${ }^{31}$. Methods that achieve phase shifting by changing the optical frequency include using an acousto-optic modulator ${ }^{32}$, rotating a half-wave plate ${ }^{33}$, analyzer ${ }^{34}$, or radial grating ${ }^{35}$, and chirping the laser frequency ${ }^{36,37}$. The frequency shifting methods are dependent upon the difference in optical path lengths between the reference and test arms, so the fixed frequency methods are generally preferred.
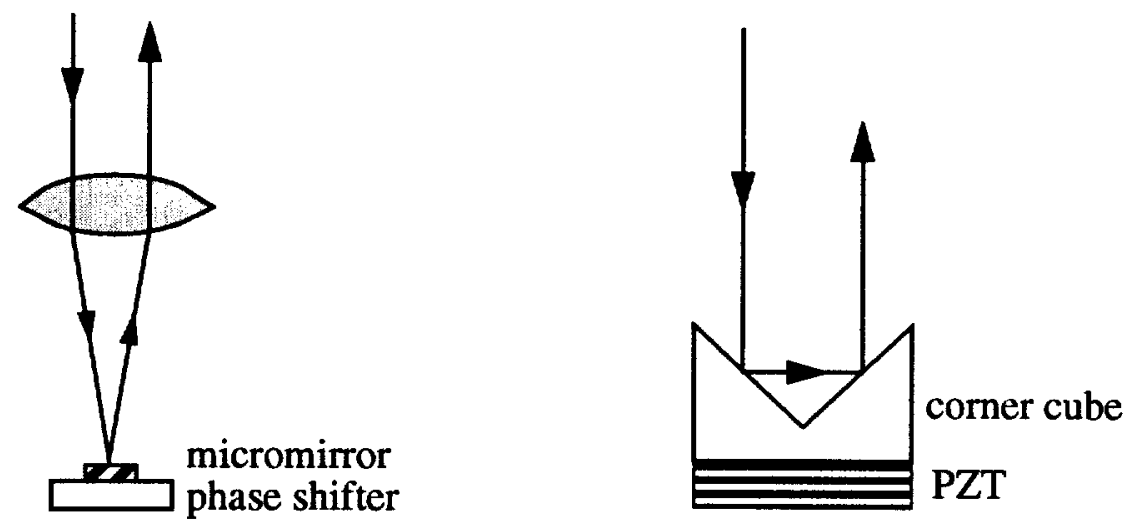

Figure 1.replacing a PZT corner cube phase shifter with a micromirror vertical actuator and a lens

In this paper, the levitation force is utilized to actively actuate a suspended mass plate in the vertical direction for controllable small vertical motions $(<2 \mu \mathrm{m})$. Other electrostatic vertical motion sensors and actuators typically utilize the parallel plate capacitor effect. Applications of this device are mostly in optics such as Fabry-Perot interferometry or phase shifting-based interferometry. Equilibrium between the electrostatic force and the folded beam flexure mechanical spring force provides the first order static equation. The electrostatic force is a function of the bias voltage applied and the position of the actuator. The mechanical spring force is a function of the position of the actuator. Combining the two results in a voltage vs. displacement curve for different mechanical spring constants. This provides a design guide for vertical comb-driven actuators. Also presented in this paper is the position sensing utilizing a parallel plate capacitive sensing configuration.

\section{PRINCIPLE OF OPERATION}

The principle of the levitation force is described in much detail by Tang et al. ${ }^{11}$. Figure 2a illustrates how the levitation force is realized. When a voltage is applied to the stationary comb fingers with respect to a grounded moving comb finger, and when the substrate is also at ground potential, the distribution of electrical field lines are asymmetric around the moving comb finger. This asymmetric distribution of field lines results in an upward levitation force indicated as the $z$ - direction. If the moving comb 
fingers are anchored to the substrate by flexure springs with a spring constant $K_{s}$, then the equilibrium position is determined by a balance between the electrostatic levitation force, the flexure spring force, and the gravity force of the suspended mass (Fig. 2b).

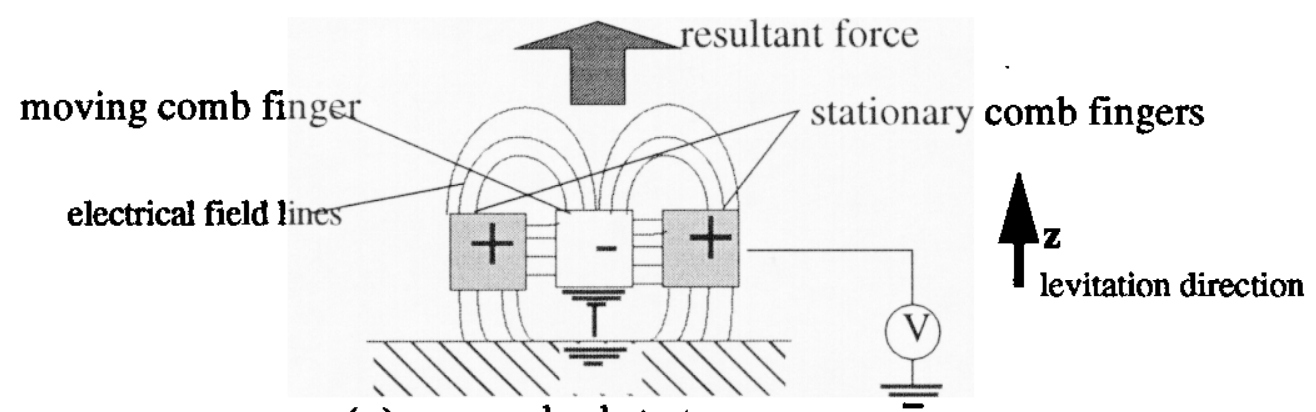

(a) ground substrate

(b)

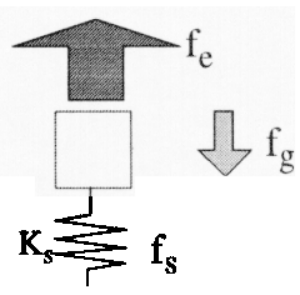

Figure 2.schematic illustrating the electrostatic levitation force; (a) the asymmetric field lines and the resultant levitation force; (b) illustration of equilibrium between electrostatic, $f_{g}$, flexure spring, $f_{s}$, and gravity forces $f_{g}$.

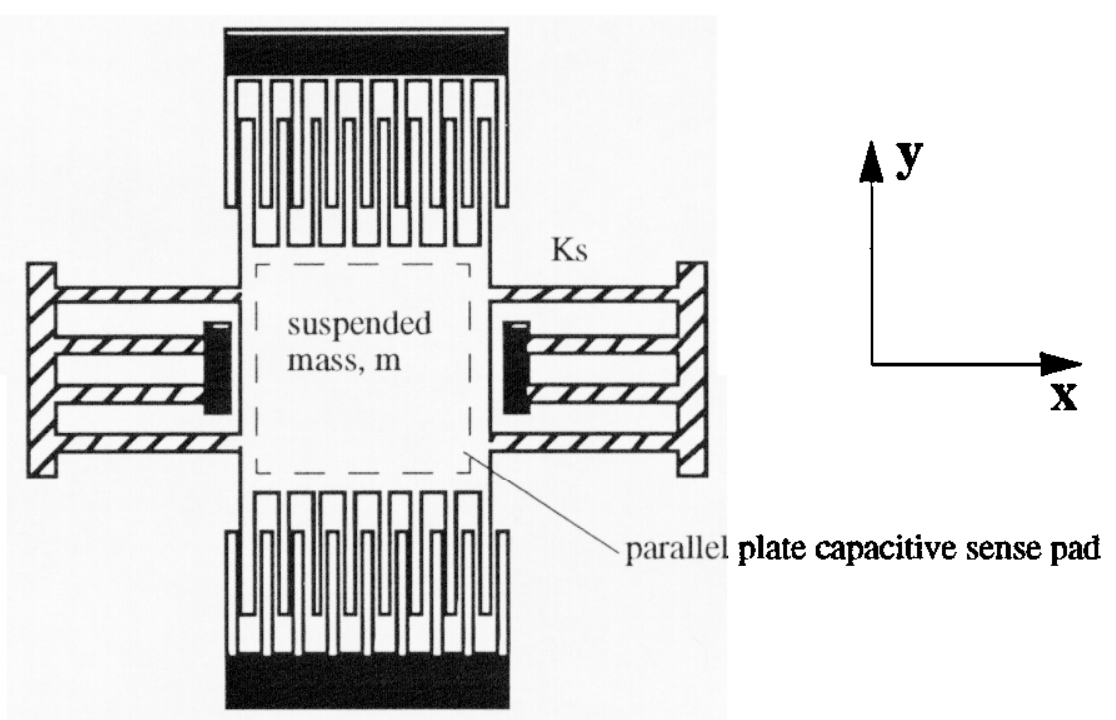

Figure 3.schematic of comb drive-folded beam flexure vertical microactuator

\section{DESIGN OF VERTICAL ACTUATOR}

A schematic of the electrostatic vertical microactuator is shown in Fig.3. The main design objective is to balance the electrostatic force, the mechanical folded beam flexure spring force, and gravity force applied to the suspended mass, $\mathrm{m}$. Design 
parameters to determine the electrostatic vertical force include the width of the comb fingers, the thickness of the comb fingers, the gaps between fingers, the position of the moving comb finger, and the vertical gap between the structures and the substrate. The mechanical folded beam suspension spring constant $K_{s}$ is determined by the dimensions of the flexures and the number of folds. Beneath the suspended mass, $\mathrm{m}$, a capacitive pad is designed for vertical position sensing using the parallel plate configuration.

The voltage-deflection response of the mirror was modeled using a combination of finite element analysis and hand calculations. Maxwell 2D, an electrostatic finite element code, was used to calculate the electrostatic forces on one comb finger at voltages ranging from 2 to $20 \mathrm{~V}$ and levitation heights from -2 to $2 \mu \mathrm{m}$. Figure 4 shows the electric field from one such simulation. Plots of electrostatic force vs. levitation height for different voltages was made from these results (see Fig. 5). From Fig. 5 it is seen that there is a neutral levitation height above the initial position at which the electrostatic force is equal to zero. In the current example this neutral position is $1.8 \mu \mathrm{m}$. A fourth order polynomial was fit to each constant voltage curve, and a force balance was used to determine the mirror's leviation height as a function of voltage. Setting the electrostatic force $\mathrm{F}_{\mathrm{e}}$ equal to the gravitational force $F_{g}$ and the suspension force $F_{s}$ results in the governing equation,

$$
F_{e}(d, v)=F_{g}+F_{s}(d)
$$

where $d$ is the levitation height. The flexure spring constant and resulting suspension force is calculated by Castigliano's theory ${ }^{1,23}$. Equation 1 leads to discrete data points for levitation heights at different applied voltages. Figure 6 shows the modeling results for one mirror design with four different suspension stiffnesses.

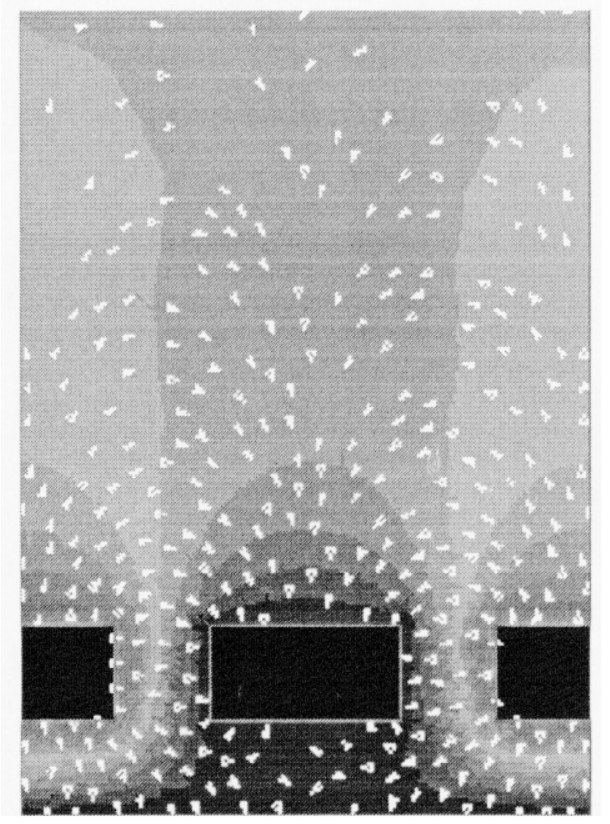

Figure 4.FEM illustrating electric field lines and equi-potential lines 


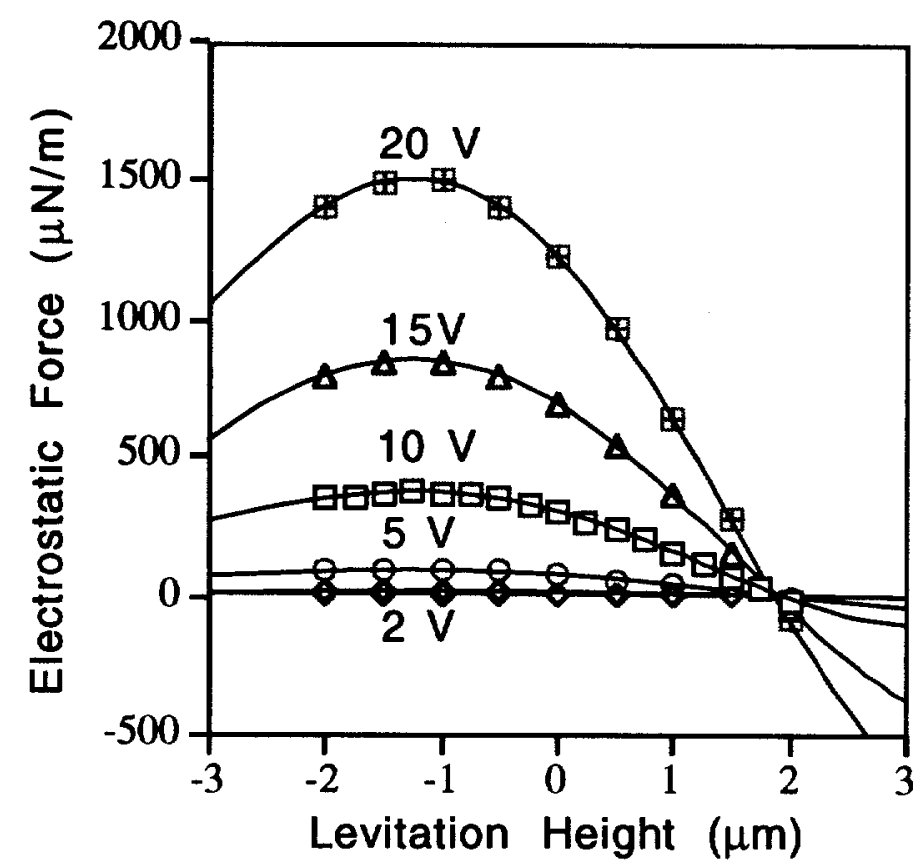

Figure 5.Electrostatic force versus levitation height plot. Mirror dimensions: $4 \mu \mathrm{m}$ wide polySi fingers, $2 \mu \mathrm{m}$ wide gaps between fingers, $2 \mu \mathrm{m}$ silicon dioxide sacrificial layer, $2 \mu \mathrm{m}$ thick mirror and levitating fingers, and 3.5 micron thick stationary fingers, with 168 fingers having $180 \mu \mathrm{m}$ actuation length each.

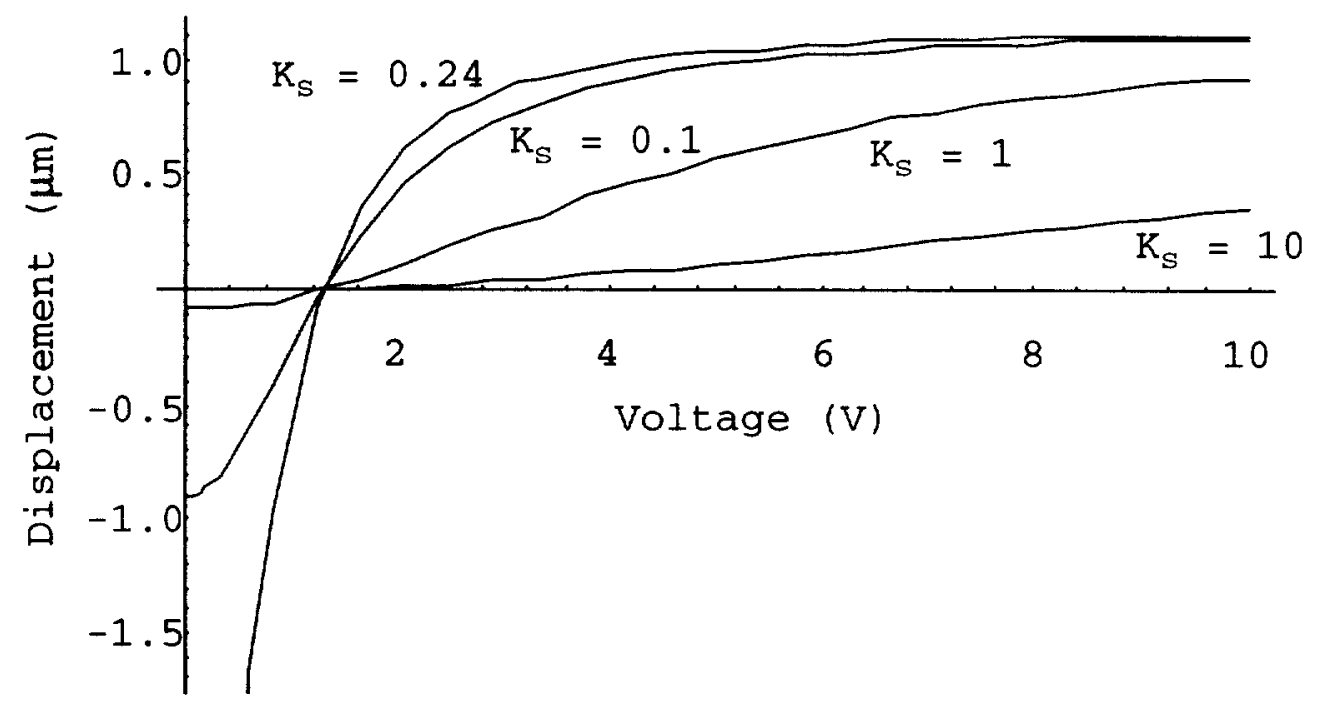

Figure 6. Voltage-displacement plots for various flexure spring constants $\left(K_{s}\right.$ in $\left.\mu \mathrm{N} / \mu \mathrm{m}\right)$. Same mirror dimensions as in Fig. 5, and the mirror mass is $9.2 \mu \mathrm{gm}$. 


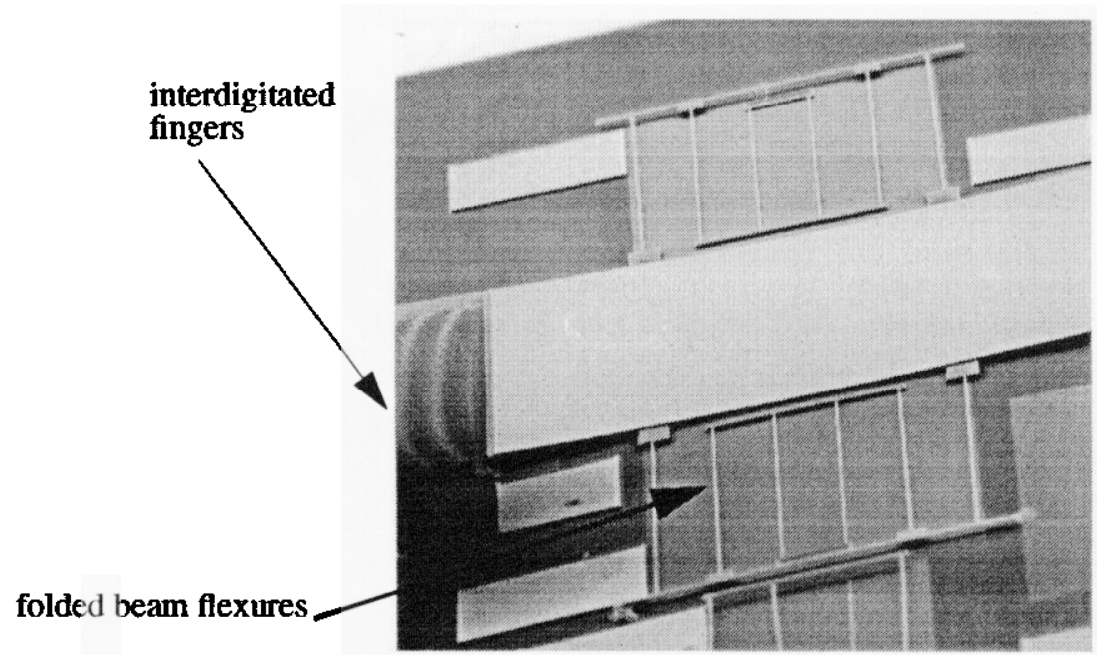

Figure 7. SEM of polysilicon micromirror

\section{MICROFABRICATION}

Polysilicon surface micromachining and SOI surface micromachining were employed to microfabricate the devices. The polysilicon process was carried out by MCNC using the MUMPS service. The polysilicon microstructures were freed from the substrate with a $\mathrm{CO}_{2}$ supercritical release ${ }^{24}$ and the surfaces were passivated with anti-stiction self-assembled monolayers ${ }^{38}$. Stress was evident from two sources: the intrinsic residual stress in the polysilicon films, and thermal residual stress from metal coatings on the polysilicon suspended mass. The former caused the suspended plate to bow downwards whereas the latter generated an upward curvature. In future work the two could be designed to compensate for each other. As for the SOI micromachining, large anchors were designed so that undercutting of the sacrificial buried oxide underneath the anchors did not completely etch away. The SOI structures have the advantage of a smoother surface for a better optical mirror surface as opposed to the polysilicon surfaces. Another advantage of the SOI process is the potential of etching the backside of the wafer to create a transmissive window or the potential to coat both sides of the suspended mass with metal thin films, avoiding residual stress induced bimetallic curvatures resulting from only coating a single side. Both the polysilicon vertical actuators and the SOI vertical actuators were successfully tested.
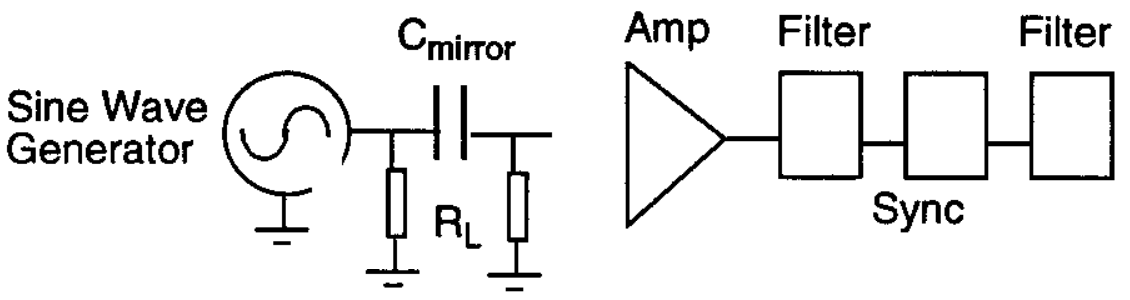

Figure 8. Circuit used to measure capacitive sensor

\section{IN SITU CAPACITIVE POSITION SENSING}

A capacitor was built into the micromirror for the purpose of measuring the displacement of the mirror above the substrate. The bottom plate of the capacitor is formed by a layer of polysilicon which is the same area as the mirror itself. The top plate 
of the sense capacitor is the mirror itself. It should be pointed out that the bottom plate is deposited on top of an oxide-nitride layer which is on top of the silicon substrate. For this reason the bottom plate has substantial (about $60 \mathrm{pF}$ ) parasitic capacitance to ground. The sensor capacitance itself is in the neighborhood of $2 \mathrm{pF}$.

The choice of the circuit to measure the capacitor had two objectives. The first objective was to mitigate the problems of parasitic capacitance. The second objective was to work at low enough drive levels as to not cause the sense capacitor to become an actuator because of its large area. A circuit that used voltages above 1 volt was originally used but had a tendency to cause electrostatic attraction of the top plate which defeated the purpose of the comb drivers. The circuit shown in Figure 8 uses a low voltage (10 to $100 \mathrm{mV}), 455 \mathrm{Khz}$ test signal to measure the sense capacitor. It should be pointed out that high frequency A.C. signals, beyond the mechanical response frequency, act like D.C. signals and still can cause problems. Because of the low amplitude, the electrostatic effects were minimized. In addition parasitics were not a problem because both ends of the capacitor are run at a fairly low impedance with respect to ground. Therefore, the parasitics are shunted by the low impedances.

The detection end of the circuit functions like a lock-in amplifier. Amplifiers with a gain of about 4000 are filtered with 4 $\mathrm{kHz}$ bandpass filters to minimize noise. The signal is synchronously detected and further low-pass filtered to remove additional clock noise. The voltage out of the detector is given by:

$$
V_{\text {out }}=V_{\text {in }} \cdot A_{v} \cdot R_{L} /\left(R_{L}+1 /\left(j \cdot \omega \cdot C_{\text {mirmor }}\right)\right)
$$

Where $V_{i n}$ is the drive voltage of the sine wave, $A_{v}$ is the voltage gain of the amplifiers, $R_{L}$ is the load resistor $(1 \mathrm{~K} \Omega), j$ is the imaginary number $V-1, \omega$ is the drive frequency in radians/second, and $C_{\text {miror }}$ is the unknown mirror capacitance. The output voltage $V_{\text {out }}$ has a linear relationship to $C_{\text {miror }}$ and an inverse relationship to the separation between top and bottom plates. A plot of the capacitive sensor is shown in Figure 9. The mirror was being driven by a square wave to measure the micromechanical response time. The longer time $(400 \mathrm{msec})$ is the time when the drive waveform returns to zero and the springs pull the mirror back and the shorter time $(50 \mathrm{msec})$ is the response time to the application of the levitation voltage. The time limitation is from the trapped air underneath the mirror.

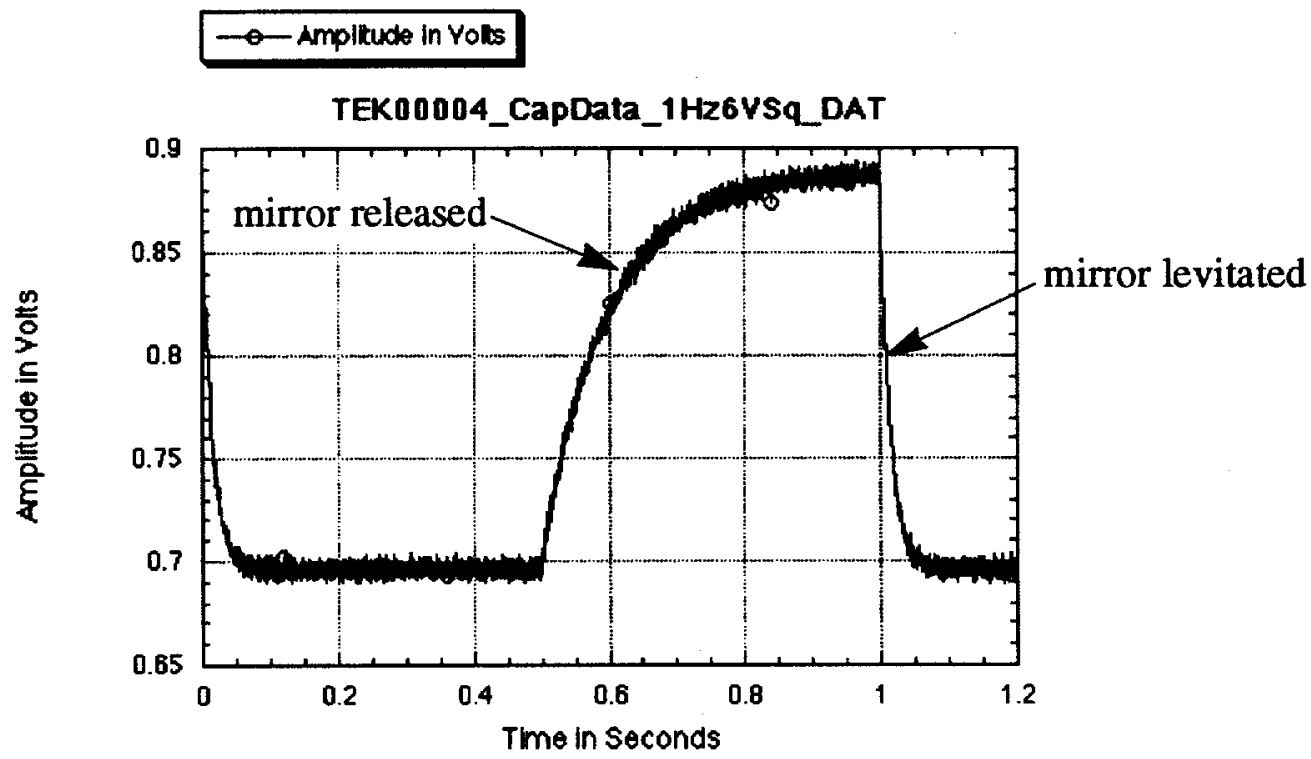

Figure 9.Capacitance sensor measurement of the mirror when driven with a square wave. Squeeze film damping slows the mirror's response upon release. 


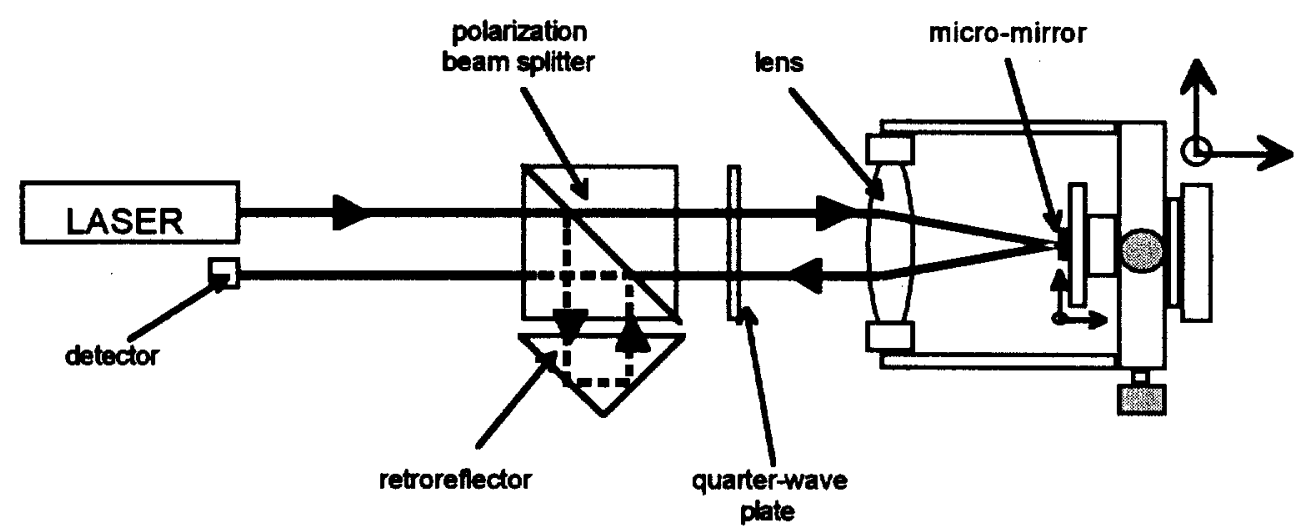

Figure 10. The distance measuring interferometer consists of a laser head, beam splitter, retroreflector (the reference arm), and quarter-wave plate plus micro-mirror assembly (the test arm).

\section{TESTING SETUP OF VERTICAL MICROMIRROR ACTUATOR}

The motion of the micro-mirror was measured using a Zygo ZMI-1000 digital heterodyne distance measuring interferometer (DMI). A diagram of the experimental setup is shown in Fig. 10. The micro-mirror was positioned at the focal point of the lens by a small XYZ translation stage mounted to the lens housing. The entire package was then positioned using a large XYZ translation stage to achieve the proper spacing and orientation of the beams input to and output from the package.

The DMI was configured for single pass operation, yielding a resolution of $2.47 \mathrm{~nm}$ on the mirror motion. A Labview program allowed taking up to 20,000 samples a rates up to $100 \mathrm{kHz}$. For most of the measurements, 1000 samples were taken at $100 \mathrm{~Hz}$.

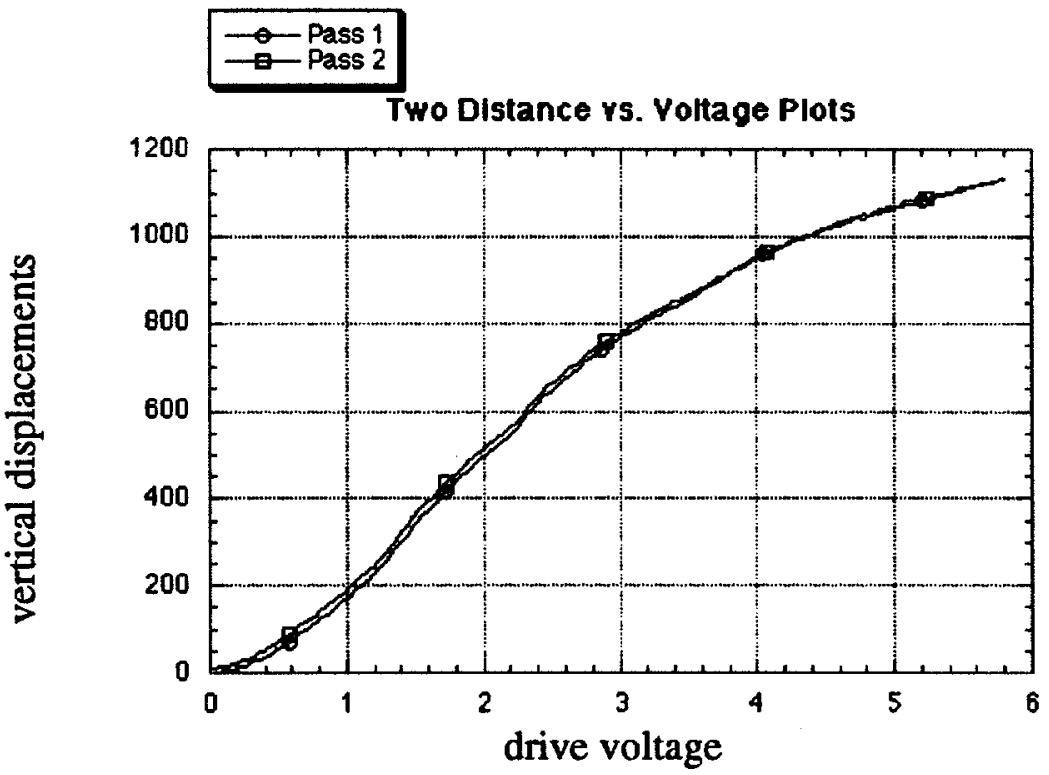

Figure 11.vertical displacement versus drive voltage

\section{TESTING RESULTS}

Optical testing of the vertical actuator was carried out on a $1 \mathrm{~mm} \times 1 \mathrm{~mm} 9.2 \mu \mathrm{gm}$ polysilicon device, with a spring constant of $0.15 \mu \mathrm{N} / \mu \mathrm{m}$, and $84 \mathrm{comb}$ fingers $2 \mu \mathrm{m}$ thick and $4 \mu \mathrm{m}$ wide. Figure 11 shows the vertical displacement versus the drive 
voltage. The maximum displacement approaches $1.2 \mu \mathrm{m}$ corresponding to the theoretical plot as indicated in Fig. 6. For dynamic responses, a square (step) input voltage illustrates the damping and time constant of the microstructure (Fig.12). Since the levitation of the suspended mass reduces the optical path distance, it is represented by a drop in amplitude. As observed in Fig. 12, the time constant for the electrostatic levitation is approximately $50 \mathrm{msec}$, and the time constant for the restoring drop is approximately $\mathbf{4 0 0} \mathrm{msec}$, matching the capacitive sensing results in Fig.9. The difference in time constants is due to the squeeze film damping effec ${ }^{39}$ required to displace the trapped air in the small gap between the suspended mass and the substrate. To reduce this damping effect, an optimization must be carried out, with the gap and the size of the suspended mass as the optimization variables.

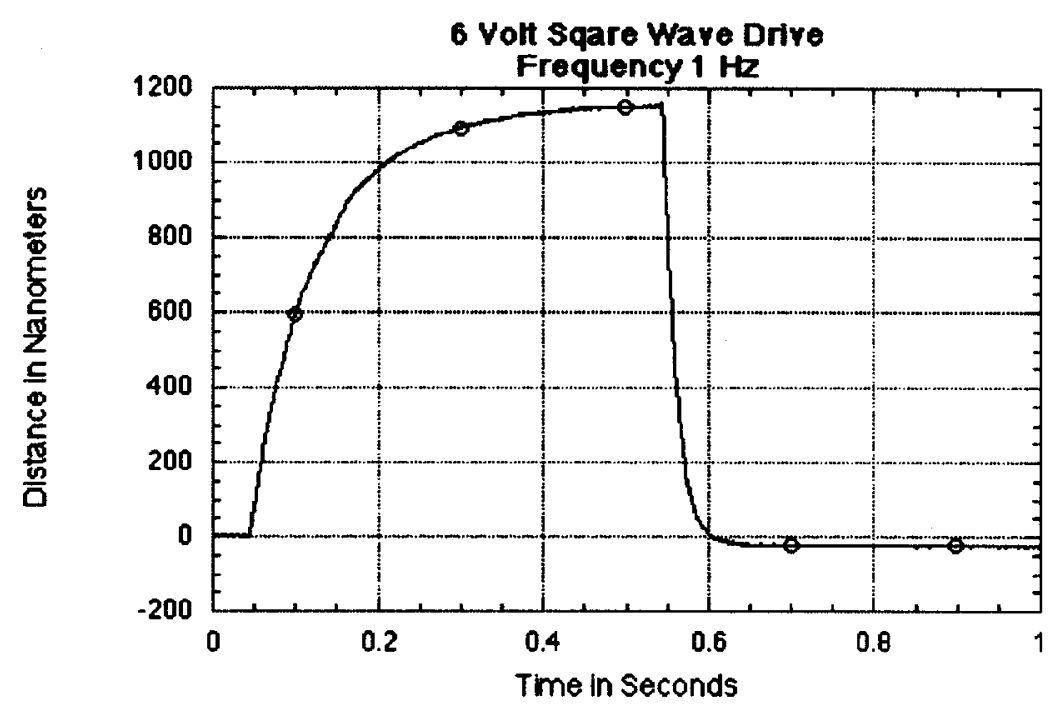

Figure 12.dynamic response of square wave input voltage

\section{CONCLUSION}

This paper explores the application of electrostatic levitation forces in comb finger drives for vertical small-displacement $(1-2 \mu \mathrm{m})$ microactuators. The layout of this microactuator is simple and standard polysilicon or SOI surface micromachining processes can be utilized. On-chip in situ capacitive position sensing provides a feedback loop to control the vertical displacement down to accuracies better than $5 \mathrm{~nm}$ resolutions. Interferometry for measuring the displacement with different input voltages was set up. These initial tests of the vertical microactuator demonstrated the match between theoretical predictions and experimental verifications. For future designs, it is desired to reduce the squeeze film damping effect to increase the speed of response by reducing the area of the suspended mass. The device presented in this paper can become an integral component in phase shifting interferometry.

\section{ACKNOWLEDGMENT}

The authors would like to thank Dr. Michael Houston and the $H$ Plus Technologies for their assistance in the supercritical release and the SAM coatings for anti-stiction treatments. Mr. Bill Benett is credited for designing the mechanical compartment for the lens-microactuator system with alignable $x-y-z$ stages. Mr. Ronald Frattaroli built this mechanical compartment. Ms. Asuncion Lemoff is appreciated for her assistance in testing of the devices. Funding from LLNL's Engineering techbase funds is appreciated. This work was performed under the auspices of the US Department of Energy by the Lawrence Livermore National Laboratory under contract no. W-7405-ENG-48. 


\section{REFERENCES}

1. Tang, W.C., Nguyen, T.-C. H., Judy, M.W., and Howe, R.T., "Electrostatic-comb drive of lateral polysilicon resonators," Sensors and Actuators, vol.A21-23, pp.328-331, 1990.

2. Fedder, G.K. and Howe, R.T., "Multimode Digital Control of a Suspended Microstructure", Jouirnal of Microelectromechanical Systems, vol.5, no.6, December, 1996.

3. W.Yun, "A Surface Micromachined Accelerometer with Integrated CMOS Detection Circuitry", Ph.D. thesis, Dept. of EECS, University of Califomia, Berkeley, Nov.1992.

4. T. A. Roessig, R.T. Howe, A.P. Pisano, and J.H. Smith, "Surface-Micromachined Resonant Accelerometer", Transducers '97, International Conference on Solid-State Sensors and Actuators, Digest of Technical Papers, vol.2, pp.859-862, Chicago, IL June16-19.

5. C. Song, "Commercial vision of silicon based inertial sensors", Transducers '97, International Conference on Solid-State Sensors and Actuators, Digest of Technical Papers, vol.2, pp.839-842, Chicago, IL June16-19, 1997.

6. B.E. Boser, and R.T. Howe, "Surface Micromachined Accelerometers," IEEE Journal of Solid-State Circuits, 31(3), pp.366-375, 1996.

7. W.A.Clark, R.T.Howe, and R.Horowitz, "Surface Micromachined Z-Axis Vibratory Rate Gyroscope", Solid-State Sensor and Actuator Workshop, Hilton Head Island, S.C., 2-6 June, 1996, pp.283-287.

8. A.P. Lee, "Impact Actuationof Micromechanical Structures", Ph.D. Thesis, Univ. of Calif., Berkeley, CA @1992.

9. L.Lin et al., "Micro Electromechanical Filters for Signal Processing", Technical Digest, IEEE MEMS Workshop, Travemunde, Germany, 4-7 Feb., 1992, pp.226-231

10.C.H.Hsu and R.S.Muller, "Micromechanical Electrostatic Voltmeter", Transducers 91, S.F., CA, 24-27 June, 1991, pp.659662.

11. Tang, W.C., Lim, M.G., and Howe, R.T., "Electrostatic Comb Drive Levitation and Control Method", Journal of Microelectromechanical Systems, vol.1, no.4, December 1992.

12.N.C. Tien, M.-H. Kiang, M.J. Daneman, O. Solgaard, K.Y. Lam, and R.S. Muller, "Actuation of polysilicon surface-micromachined mirrors", Proc. SPIE, vol.2687, pp.53, San Jose, CA, Jan.30-31, 1996

13. K.S.J. Pister, M.W. Judy, S.R. Burgett, and R.S. Fearing, "Microfabricated Hinges: $1 \mathrm{~mm}$ Vertical Features with Surface Micromachining," Transducers 91, San Francisco, CA, U.S.A., June 1991, in paper substitutions.

14.O.Solgaard, M.Daneman, N.C. Tien, A. Friedberger, R.S. Muller, and K.Y. Lau, "Optoelectronic packaging using silicon surface-micromachined alignment mirrors," IEEE Photonics Technology Letters, vol.7, no.1, pp.41-43, 1995.

15.M.-H. Kiang, O. Solgaard, R.S. Muller, K.Y. Lau, "Surface-micromachined electrostatic-comb driven scanning micromirrors for barcode scanners," Proc. 1996 IEEE Microelectromechanical Systems Conference, San Diego, CA, Feb.11, 1996.

16.M.-H. Kiang, O. Solgaard, R.S. Muller, and K.Y. Lau, "Actuated polysilicon micromirrors for raster-scanning displays," Transducers '97, International Conference on Solid-State Sensors and Actuators, Digest of Technical Papers, vol.2, pp.323-326, Chicago, IL, June 16-19, 1997.

17.L.J. Hornbeck, "Digital light processing and MEMS: reflecting the digital display needs of networked society," Proc. SPIE, vol.2783, pp.2-13, 1996.

18. J.H. Comtois, V.M. Bright, S. Gustafson, and M.A. Michalicek, "Implementation of hexagonal micromirror arrays as phase-mostly spatial light modulators," Proc. SPIE, vol.2641, pp.76-87, 1995.

19.M.-H. Kiang, O. Solgaard, R.S. Muller, and K.Y. Lau, "Silicon-micromachined micromirrors with integrated high-precision actuators for external-cavity semiconductor lasers," IEEE Photonics Technology Letters, vol.8, no.1, Jan. 1996.

20.L.J. Hornbeck, "Projection displays and MEMS: Timely convergence for a bright future," Proceedings of SPIE, vol.2639, pp.2, 1995.

21. Apte, R.B., Sandejas, F.S.A., Banyai, W.C., and Bloom, D.M., "Deformable Grating Light Valves for High Resolution Displays", Technical Digest of Solid-State Sensor and Actuator Workshop, Hilton Head Island, South Carolina, June13-16, 1994

22.N.F. Raley, D.R. Ciarlo, J.C. Koo, B. Beiriger, J. Trujilo, C. Yu, G. Loomis, and R. Chow, "A Fabry-Perot microinterferometer for visible wavelengths," Technical Digest of Solid-State Sensor and Actuator Workshop, pp.170, Hilton Head Island, South Carolina, June, 1992.

23. A.P. Boresi and O.M. Sidebottom, "Advanced mechanics of materials," John Wiley \& Sons, 4th edition, 1985.

24.G. Mullhern, D. Soane, and R.T.Howe, "Supercritical carbon dioxide drying of microstructures," Transducers '93, Interna- 
tional Conference on Solid-State Sensors and Actuators, Digest of Technical Papers, pp.296-299, Yokohama, Japan, June 7-10, 1993.

25.] D. Malacara, Optical Shop Testing 2nd Ed., (Wiley, New York, 1992) p1-94.

26.K. Creath, in Interferogram Analysis, edited by D.W. Robinson and G.T. Reid, (Institute of Physics Publishing, Philadelphia, 1993) p97-99.

27.J.H. Bruning, D.R. Herriott, J.E. Gallagher, D.P. Rosenfeld, A.D. White, and D.J. Brangaccio, "Digital wavefront measuring interferometer for testing optical surfaces and lenses," Appl. Opt., Vol. 13, No. 11, p2693-2703.

28.J. Schwider in Progress in Optics XXVIII, edited by E. Wolf, (Elsevier Science Publication, New York, 1990), p296-297.

29. H. Medecki, E. Tejnil, K.A. Goldberg, and J. Bokor, " Phase-shifting point diffraction interferometer," Opt. Lett., Vol. 21, No. 19, p1526-1528.

30.K.S. Lau, K.H. Wong, T.L. Chan, and S.K. Yeung. "An economical piezoelectric phase modulator for fiber optic sensors," Appl. Opt., Vol. 35, No. 34, p6836-6838.

31. T.A. Maldonado in Handbook of Optics Vol. II, 2nd Ed., edited by M. Bass, (McGraw-Hill, 1995) p13.17-13.18.

32. R. Crane, "New developments in interferometry - V. Interference phase measurement," Appl. Opt., Vol. 8, No. 3, p538-542.

33.N.A. Massie, R.D. Nelson, and S. Holly, "High-performance real-time heterodyne interferometry," Appl. Opt., Vol. 18, No. 11, p1797-1803.

34.H.Z. Hu, "Polarization heterodyne interferometry using a simple rotating analyzer. 1: Theory and error analysis," Appl. Opt., Vol. 22, No. 13, p2052-2056.

35.W.H. Stevenson, "Optical frequency shifting by means of a rotating diffraction grating," Appl. Opt., Vol. 9, No. 3, p649652.

36. Y. Ishii, J. Chen, and K. Murata, "Digital phase-measuring interferometry with a tunable laser diode," Opt. Lett., Vol. 12, No. 4, p233-235.

37.R.G. Pilston and G.N. Steinberg, "New developments in interferometry - VII. Multiple-wavelength interferometry with tunable source," Appl. Opt., Vol. 8, No. 3, p553-556.

38.M.R. Houston, R.Maboudian, and R.T. Howe, "Self-assembled monolayer films as durable anti-stiction coatings for polysilicon microstructures," Technical Digest of Solid-State Sensor and Actuator Workshop, pp. 42-47, Hilton Head Island, South Carolina, June 2-6, 1996

39. Y.-J. Yang, M.-A. Gretilat, and S.D.Senturia, "Effect of air damping on the dynamics of nonuniform deformations of microstructures," Transducers '97, International Conference on Solid-State Sensors and Actuators, Digest of Technical Papers, vol.2, pp.1093, Chicago, IL, June 16-19, 1997. 


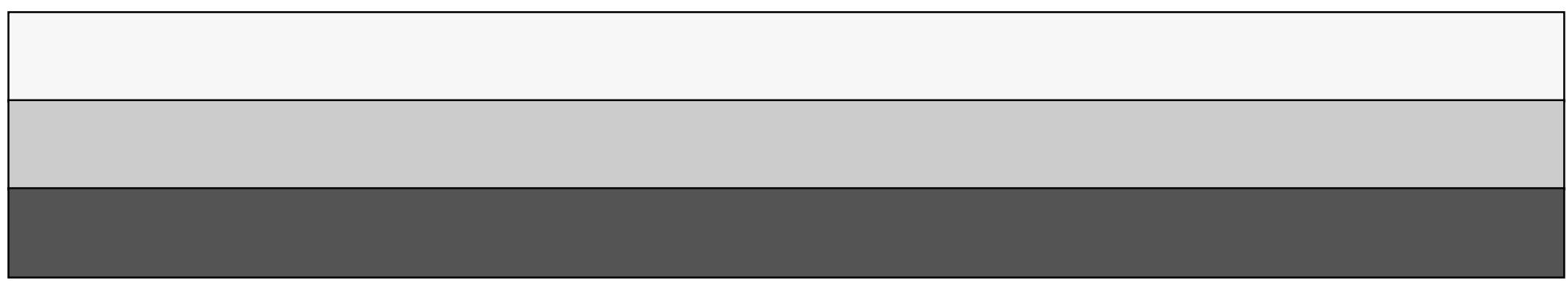

